\title{
Hubungan Pemberian ASI, MP-ASI, Imunisasi dan Riwayat Penyakit terhadap Pertumbuhan Anak Usia 24-36 Bulan
}

\author{
Rayhana $^{1}$, Utami Rizalvi \\ 1) Departemen Biomedik, Fakultas Kedokteran dan Kesehatan, Universitas Muhammadiyah Jakarta \\ 2) Program Studi Pendidikan Dokter, Fakultas Kedokteran dan Kesehatan, Universitas Muhammadiyah Jakarta \\ *raykud@gmail.com
}

\begin{abstract}
Background: The golden period of a child's growth and development is formed in the first 1000 days of his life. In this period the provision of nutrition, parenting, and disease prevention will affect the growth of children in the future. Purposes: to know the dominant factor that affects growth in children 24-36 months in Posyandu village Cipinang Muara RW 03. Method: The research on using cross-sectional design was done in Posyandu of Cipinang Muara Village RW 03 in October 2019. A sample of 97 mother-daughter was taken with a total sampling technique. Child growth is measured by anthropometry using weight indicators according to age (W/A). Independent variables (breast milk, food substitute breast milk, mother and child immunizations, and maternal and child disease histories) as well as dependent variables (child growth) were analyzed using double logistic regression. Result: Child growth based on nutritional status is well experienced by as much as $81.4 \%$. The dominant factor affecting the growth of children with W/A indicators is the history of children's illness (OR: 3.239 95\% CI: 1,131-9,272). Children with a history of 3 times higher risk of illness have less nutritional status than children who do not have a history of illness. Conclusion: Should consider the intake of mother nutrition during pregnancy and children nutrition after the age of 6 months so that the child can grow healthy and avoid illness.
\end{abstract}

Keywords: breast milk, MP-ASI, Immunisation, Disease history, Growth

\begin{abstract}
ABSTRAK
Latar Belakang: Periode emas masa pertumbuhan dan perkembangan anak dibentuk pada 1000 hari pertama kehidupannya. Dalam masa ini pemberian nutrisi, pola asuh, dan pencegahan penyakit akan berpengaruh untuk pertumbuhan anak dimasa yang akan datang. Tujuan: untuk mengetahui faktor dominan yang mempengaruhi pertumbuhan pada anak 24-36 bulan di Posyandu Kelurahan Cipinang Muara RW 03. Metode: Penelitian menggunakan desain cross-sectional dilakukan di Posyandu Kelurahan Cipinang Muara RW 03 pada bulan Oktober 2019. Sampel sebanyak 97 ibu-anak diambil dengan teknik total sampling. Pertumbuhan anak diukur dengan antropometri menggunakan indikator berat badan menurut umur $(\mathrm{BB} / \mathrm{U})$. Variabel independen (pemberian ASI, MP-ASI, imunisasi ibu dan anak, serta riwayat penyakit ibu dan anak) serta variabel dependen (pertumbuhan anak) dianalisis menggunakan regresi logistik ganda. Hasil: Pertumbuhan anak berdasarkan status gizi baik dialami oleh sebanyak 81,4\%. Faktor dominan yang berpengaruh terhadap pertumbuhan anak dengan indikator $\mathrm{BB} / \mathrm{U}$ adalah riwayat penyakit anak (OR: 3,239 95\% CI: 1,131-9,272). Anak yang memiliki riwayat penyakit berisiko 3 kali lebih tinggi mengalami status gizi kurang dibandingkan anak yang tidak memiliki riwayat penyakit.
\end{abstract}


Kesimpulan: Perlu diperhatikan asupan nutrisi ibu selama kehamilan dan nutrisi anak setelah usia 6 bulan sehingga anak dapat tumbuh dengan sehat dan terhindar dari penyakit.

Kata kunci: ASI, MP-ASI, Imunisasi, Riwayat penyakit, Pertumbuhan

\section{PENDAHULUAN}

Pada periode 1000 Hari Pertama Kehidupan beberapa hal sensitif sering muncul terhadap bayi, hal ini dapat berdampak secara permanen dan tidak dapat disembuhkan meskipun dalam jangka panjang. Adapun dalam jangka pendek permasalahan gizi pada periode ini yang bisa muncul contohnya gangguan perkembangan otak, gangguan pada kecerdasan bayi, gangguan pertumbuhan fisik, bahkan gangguan metabolisme dalam tubuh.

Dampak jangka panjang masalah gizi yaitu penurunan kognitif dan hasil belajar, penurunan imunitas tubuh dan risiko tinggi terjadinya penyakit degeneratif dan kecacatan diusia senja, serta produktivitas ekonomi rendah yang disebabkan oleh kualitas kerja yang tidak bersaing. Banyak faktor yang dapat menyebabkan gizi kurang, yaitu kurangnya asupan zat gizi, penyakit infeksi, lingkungan, akses pelayanan kesehatan, dan lain-lain (1).

Hasil Riset Kesehatan Dasar (Riskesdas) Kementerian Kesehatan 2018 diperoleh $17,7 \%$ balita usia dibawah 60 bulan masih mengalami masalah gizi, data tersebut meliputi balita dengan gizi buruk sebesar 3,9\% dan gizi kurang sebesar $13,8 \%$ (2).

Prevalensi balita dengan gizi kurang di DKI Jakarta tahun 2018 sebanyak 0,6\% balita, dibandingkan tahun sebelumnya sebesar 2,92\%. Persentase balita gizi kurang tertinggi di kepulauan seribu sebesar 1,8\%, disebabkan diwilayah tersebut relatif rendah dan kurangnya pengetahuan gizi pada anak di masyarakat.
Sedangkan di wilayah Jakarta Timur persentase balita dengan gizi kurang sebesar 0,5\% (3).

Berdasarkan literatur tersebut tujuan penelitian ini untuk mengetahui faktor yang mempengaruhi pertumbuhan anak 2-3 tahun di Posyandu Kelurahan Cipinang Muara RW 03 Jakarta Timur.

\section{METODE}

Penelitian ini adalah analitik deskriptif menggunakan desain cross-sectional. Lokasi penelitian di Posyandu Kelurahan Cipinang Muara RW 03 pada OktoberNovember 2019. Populasi dalam penelitian ini merupakan seluruh anak di Posyandu Kelurahan Cipinang Muara RW 03. Besar sampel dihitung menggunakan rumus Lemeshow dengan metode total sampling dan diperoleh sebanyak 97 ibu-anak yang memenuhi kriteria inklusi, yaitu ibu yang memiliki anak berusia 24-36 bulan (4).

Data yang digunakan pada penelitian ini adalah data primer dan sekunder. Pertumbuhan anak diukur dengan antropometri menggunakan indikator berat badan menurut umur $(\mathrm{BB} / \mathrm{U})$ parameter $\mathrm{z}$ score yang digunakan untuk kriteria gizi kurang -3 SD hingga <-2 SD dan gizi baik 2 SD hingga $2 \mathrm{SD}$, alat ukur menggunakan timbangan badan. Sedangkan untuk variabel independen (Pemberian ASI, MPASI, imunisasi ibu dan anak, riwayat penyakit ibu dan anak) diukur menggunakan kuesioner dengan teknik wawancara. Setelah melakukan uji validitas dan realibilitas dengan cronbach's alpha 0,670, kuesioner dapat digunakan pada penelitian ini. 
Analisis bivarait menggunakan uji chi square, analisis multivariat menggunakan regresi logistik dengan program SPSS. Penelitian ini sudah mendapatkan izin pelaksanaan penelitian oleh Pemerintah Provinsi DKI Jakarta Kota Administrasi Jakarta Timur dan uji etik oleh Komite Etik FKK UMJ dengan Nomor 104A/PE/KE/FKK-UMJ/X/2019 yang diterbitkan pada bulan Oktober 2019.

\section{HASIL}

Hasil penelitian yang dilakukan di Posyandu Kelurahan Cipinang Muara RW 03 menunjukkan dari 97 anak, terdapat sebesar 18,6\% anak dengan gizi kurang. Angka ini menunjukkan bahwa anak dengan gizi kurang di Posyandu Kelurahan Muara RW 03 masih tinggi dibandingkan dengan Riskesdas (2018) sebesar 13,8\% (2). Berdasarkan hasil penelitian ini, mayoritas ibu berpendidikan SMA/SLTA yaitu sebesar 52,6\%, dan ibu dengan pekerjaan ibu rumah tangga sebesar 75,3\%. Pola pemberian ASI didominasi oleh pemberian ASI secara eksklusif sebesar $72,2 \%$, dengan lama pemberian ASI didominasi oleh pemberian ASI selama 2 tahun sebesar $55,7 \%$. Anak yang pemberian MP-ASI sesuai dengan usianya sebesar $75,3 \%$, Pemberian imunisasi anak secara lengkap sebanyak 89,7\%. Ibu yang mendapatkan imunisasi tetanus toxoid sebesar 59,8\%, sedangkan untuk imunisasi TORCH hanya $25,8 \%$ ibu yang mendapatkannya. Ibu dominan tidak mempunyai penyakit prenatal sebesar $66,0 \%$, sedangkan anak yang tidak mempunyai riwayat penyakit sebesar $67,0 \%$ (Tabel 1).
Tabel 1. Gambaran Pertumbuhan Anak serta Karakteristik Ibu dan Anak

\begin{tabular}{|c|c|c|}
\hline Variabel & $\mathbf{n}$ & $\%$ \\
\hline \multicolumn{3}{|l|}{$\mathrm{BB} / \mathrm{U}$} \\
\hline Gizi Kurang & 18 & 18,6 \\
\hline Gizi Baik & 79 & 81,4 \\
\hline \multicolumn{3}{|l|}{ Pendidikan Ibu } \\
\hline SD & 12 & 12,4 \\
\hline SMP/SLTP & 12 & 12,4 \\
\hline SMA/SLTA & 51 & 52,6 \\
\hline Sarjana & 22 & 22,7 \\
\hline \multicolumn{3}{|l|}{ Pekerjaan } \\
\hline IRT & 73 & 75,3 \\
\hline PNS & 6 & 6,2 \\
\hline Pedagang & 11 & 11,3 \\
\hline Lain-lain & 7 & 7,2 \\
\hline \multicolumn{3}{|l|}{ Pola beri ASI } \\
\hline Eksklusif & 70 & 72,2 \\
\hline Non Eksklusif & 27 & 27,8 \\
\hline \multicolumn{3}{|l|}{ Lama beri ASI } \\
\hline 2 Tahun & 54 & 55,7 \\
\hline$<2$ Tahun & 43 & 44,3 \\
\hline \multicolumn{3}{|l|}{ MP-ASI } \\
\hline Sesuai & 73 & 75,3 \\
\hline Tidak sesuai & 24 & 24,7 \\
\hline \multicolumn{3}{|l|}{ Imunisasi anak } \\
\hline Lengkap & 87 & 89,7 \\
\hline Tidak lengkap & 10 & 10,3 \\
\hline \multicolumn{3}{|l|}{ Imun TT Ibu } \\
\hline Ya & 58 & 59,8 \\
\hline Tidak & 39 & 40,2 \\
\hline \multicolumn{3}{|l|}{ Imun TORCH ibu } \\
\hline Ya & 25 & 25,8 \\
\hline Tidak & 72 & 74,2 \\
\hline \multicolumn{3}{|l|}{$\begin{array}{l}\text { Riwayat penyakit } \\
\text { prenatal ibu }\end{array}$} \\
\hline Ya ada & 33 & 34,0 \\
\hline Tidak ada & 64 & 66,0 \\
\hline \multicolumn{3}{|c|}{ Riwayat penyakit Anak } \\
\hline Ya ada & 32 & 33,0 \\
\hline Tidak ada & 65 & 67,0 \\
\hline
\end{tabular}

Sumber: Data Primer 
Hasil analisis chi-square didapatkan bahwa dari 8 variabel bebas, terdapat 2 variabel yang berhubungan signifikan terhadap pertumbuhan anak usia 24-36 bulan (nilai p-value $<0,05$ ) yaitu pemberian MP-ASI dan riwayat penyakit pada anak, sedangkan untuk variabel Pola pemberian ASI eksklusif, lama pemberian ASI, pemberian imunisasi pada anak dan ibu serta riwayat penyakit ibu tidak berhubungan signifikan terhadap pertumbuhan anak usia 24-36 bulan (Tabel 2). Selanjutnya berdasarkan hasil seleksi kandidat, hanya 2 variabel yaitu pemberian MP-ASI dan riwayat penyakit anak yang masuk dalam analisis multivariat dengan regresi logistik ganda. Model akhir uji regresi logistik menunjukkan pertumbuhan anak 24-36 bulan paling dominan dipengaruhi oleh riwayat penyakit anak (pvalue $=0,029$; oods ratio $=3,239 ; 95 \% \mathrm{CI}=$ $1,131-9,272)$. Anak yang memiliki riwayat penyakit berisiko 3 kali lebih besar mengalami perumbuhan yang terhambat atau gizi kurang dibandingkan anak yang tidak memiliki riwayat penyakit.

Tabel 2. Hubungan Karakteristik Ibu dan Anak dengan Pertumbuhan Anak Indikator BB/U

\begin{tabular}{|c|c|c|c|c|c|}
\hline \multirow[t]{2}{*}{ Karakteristik } & \multicolumn{2}{|c|}{ Gizi Kurang } & \multicolumn{2}{|c|}{ Gizi Baik } & \multirow[t]{2}{*}{ p-value } \\
\hline & $\mathbf{n}$ & $\%$ & $\mathrm{n}$ & $\%$ & \\
\hline \multicolumn{6}{|l|}{ Pola beri ASI } \\
\hline Eksklusif & 56 & 80,0 & 14 & 20,0 & 0,556 \\
\hline Non Eksklusif & 23 & 85,2 & 4 & 14,8 & \\
\hline \multicolumn{6}{|l|}{ Lama beri ASI } \\
\hline 2 Tahun & 43 & 79,0 & 11 & 20,4 & 0,607 \\
\hline$<2$ Tahun & 36 & 83,7 & 7 & 83,7 & \\
\hline \multicolumn{6}{|l|}{ MP-ASI } \\
\hline Sesuai & 17 & 23,3 & 56 & 80,0 & $\mathbf{0 , 0 3 7}$ \\
\hline Tidak sesuai & 1 & 8,3 & 23 & 91,7 & \\
\hline \multicolumn{6}{|l|}{ Imunisasi anak } \\
\hline Lengkap & 15 & 17,2 & 72 & 82,8 & 0,326 \\
\hline Tidak lengkap & 3 & 30,0 & 7 & 70,0 & \\
\hline \multicolumn{6}{|l|}{ Imun TT Ibu } \\
\hline Ya & 9 & 15,5 & 49 & 84,5 & 0,348 \\
\hline Tidak & 9 & 23,1 & 30 & 76,9 & \\
\hline \multicolumn{6}{|l|}{ Imun TORCH ibu } \\
\hline Ya & 4 & 16,0 & 21 & 84,0 & 0,789 \\
\hline Tidak & 14 & 19,4 & 58 & 80,6 & \\
\hline \multicolumn{6}{|l|}{$\begin{array}{l}\text { Riwayat penyakit } \\
\text { prenatal ibu }\end{array}$} \\
\hline Ya ada & 6 & 28,2 & 27 & 81,8 & 0,946 \\
\hline Tidak ada & 12 & 18,8 & 52 & 81,3 & \\
\hline \multicolumn{6}{|c|}{ Riwayat penyakit Anak } \\
\hline Ya ada & 10 & 31,3 & 22 & 68,8 & $\mathbf{0 , 0 2 4}$ \\
\hline Tidak ada & 8 & 12,3 & 57 & 87,7 & \\
\hline
\end{tabular}




\section{PEMBAHASAN}

Kecukupan asupan makanan sejak terutama pada 1000 Hari Pertama Kehidupan (1000 HPK) yaitu periode kehamilan hingga bayi berusia 2 (dua) tahun berpengaruh terhadap status gizi balita. Pada penelitian ini menunjukkan tidak adanya hubungan antara pemberian ASI eksklusif dengan pertumbuhan anak. Hal ini didukung oleh penelitian Irot, dkk (2017) bahwa ASI eksklusif bukan faktor risiko pertumbuhan anak (5). Meskipun demikian, penelitian lainnya yang dilakukan oleh Purba, dkk menunjukkan ada hubungan ASI eksklusif terhadap pertumbuhan anak. Balita dengan ASI eksklusif akan meningkatkan kemampuan motorik serta pertumbuhan anak (6). Hasil penelitian diperoleh bahwa tidak ada hubungan lamanya pemberian ASI terhadap pertumbuhan anak. Hasil tersebut sesuai dengan penelitian Yocom, dkk (2018) yang menunjukkan tidak ada hubungan lama pemberian ASI terhadap pertumbuhan balita (7).

Pemberian MP-ASI adalah pemberian makanan pelengkap yang dimulai ketika ASI saja sangat kurang dalam pemenuhan gizi anak, sehingga makanan dan cairan lain diperlukan bedampingan dengan pemberian ASI untuk memberi nutrisi tambahan yang tidak cukup hanya melalui ASI. Pada penelitian ini menunjukkan bahwa pemberian MP-ASI berhubungan terhadap pertumbuhan anak. Hasil penelitian sesuai dengan hasil yang didapatkan Sulistyorini (2015) yaitu pemberian MP-ASI yang sesuai berhubungan terhadap status gizi balita (8). Namun tidak sejalan dengan penelitian Herlistia dan Muniroh (2015) menunjukkan bahwa MP-ASI tidak berhubungan terhadap status gizi (9).

Imunisasi adalah satu dari upaya kesehatan yang paling eksekutif dan efisien dibandingkan dengan upaya kesehatan lainnya. Hasil penelitian ini menunjukkan imunisasi dasar lengkap anak tidak berhubungan terhadap pertumbuhan anak. Hayyudini, dkk (2017) mendapatkan hasil yang sama yaitu tidak ada hubungan imunisasi dasar lengkap terhadap pertumbuhan anak (10). Sedangkan Picauly dan Toy memperoleh hasil ada hubungan pemberian imunisasi dasar anak terhadap pertumbuhan anak berdasarkan BB/U (11).

Salah satu masalah pertumbuhan anak adalah adanya infeksi pada ibu saat masa kehamilan yang dapat mengganggu pertumbuhan dan perkembangan bayi. Salah satu pencegahan dapat dilakukan dengan imunisasi ibu. Hasil penelitian ini diperoleh tidak adanya hubungan yang bermakna pada imunisasi prenatal dan imunisasi TORCH ibu terhadap pertumbuhan anak berdasarkan BB/U. Selain itu riwayat penyakit prenatal ibu tidak menunjukkan hubungan yang bermakna dengan pertumbuhan anak.

Dalam masa pertumbuhannnya balita memerlukan nutrisi adekuat, ketika nutrisi kurang memudahkan balita untuk terkena penyakit sehingga dapat menyebabkan pertumbuhan balita terganggu. Pada penelitian ini menunjukkan adanya hubungan yang signifikan antara riwayat penyakit anak terhadap pertumbuhan anak. Hasil yang sama diperoleh Pusung (2018) menyatakan terdapat hubungan signifikan pada riwayat penyakit anak terhadap status pertumbuhan (12). Pada penelitian Kasim (2019) diperoleh data yang tidak sesuai dengan hasil penelitian ini yaitu riwayat penyakit anak tidak berhubungan dengan status gizi (13).

\section{KESIMPULAN}

Faktor yang berhubungan bermakna atau mempengaruhi pertumbuhan anak 
berdasarkan $\mathrm{BB} / \mathrm{U}$ adalah pemberian MPASI dan riwayat penyakit anak. Riwayat penyakit merupakan faktor dominan yang berhubungan dengan pertumbuhan anak. Anak dengan riwayat penyakit berisiko 3 kali lebih tinggi mengalami perumbuhan yang terhambat atau gizi kurang dibandingkan anak tanpa riwayat penyakit.

\section{UCAPAN TERIMAKASIH}

Penulis berterima kasih kepada Fakultas Kedokteran dan Kesehatan Universitas Muhammadiyah Jakarta dan semua pihak yang membantu dalam penelitian dan penyusunan artikel ilmiah ini.

\section{KONFLIK KEPENTINGAN}

Penulis menyatakan tidak memiliki konflik kepentingan, dan tidak ada afiliasi atau koneksi dengan atau dengan entitas atau organisasi apa pun, yang dapat menimbulkan pertanyaan bias dalam hasil penelitian.

\section{REFERENSI}

1. Blössner M, De Onis M, Prüss-Üstün A. Malnutrition: quantifying the health impact at national and local levels / Monika Blössner and Mercedes de Onis [Internet]. Geneva PP - Geneva: World Health Organization; 2005. (Environmental burden of disease series / series editors: Annette Prüss-Ustun ... [et al.]; no. 12). Available from: https://apps.who.int/iris/handle/106 65/43120

2. Badan Penelitian dan Pengembangan Kesehatan Kementerian Kesehatan Republik. Riset Kesehatan Dasar 2018. Jakarta; 2018.

3. Bidang Perencanaan dan Pembiayaan Dinas Kesehatan Provinsi DKI Jakarta. Profil Kesehatan Provinsi DKI Jakarta Tahun 2018. Jakarta; 2018.
4. Lemeshow S, David WHJ. Besar Sampel dalam Penelitian Kesehatan (terjemahan). Yogyakarta: Gadjahmada University Press; 1997.

5. Irot RA, Kapantow NH, Punuh MI. Hubungan antara Pemberian ASI Eksklusif dengan Status Gizi Bayi Usia 6-12 bulan di Wilayah Kerja Puskesmas Walantakan Kecamatan Langowan Utara Kabupaten Minahasa. Kesmas [Internet]. 2017;6(3):1-9. Available from: https://ejournal.unsrat.ac.id/index.p hp/kesmas/article/view/23050

6. Purba EA, Kapantow $\mathrm{NH}$, Momongan N. Hubungan Antara Pemberian ASI Eksklusif dengan Status Gizi Bayi 6-12 bulan di Wilayah Kerja Puskesmas Tatelu Kecamatan Dimembe Kabupaten Minahasa Utara. Kesmas [Internet]. 2017;6(4). Available from: https://ejournal.unsrat.ac.id/index.p $\mathrm{hp} /$ kesmas/article/view/23102

7. Yocom JF, Punuh MI, Malonda NSH. Hubungan Antara Riwayat Pemberian Asi dengan Status Gizi Anak Usia 24-59 bulan di Kecamatan Pasan Kabupaten Minahasa Tenggara. J Kesmas. 2018;7(3):1-8.

8. Sulistyorini D. Hubungan antara pola pemberian makanan pendamping asi (MP-ASI) dengan status gizi balita usia 7-24 bulam di wilayah kerja puskesmas Pucangsawit kecamatan Jebres kota Surakarta. Universitas Muhammadiyah Surakarta; 2015.

9. Herlistia BHR, Muniroh L. Hubungan Pemberian Makanan Pendamping Asi (Mp-Asi) Dan Sanitasi Rumah Dengan Status Gizi Bayi Keluarga Miskin Perkotaan. Media Gizi Indones [Internet]. 2016;10(1):76-83. Available from: https://ejournal.unair.ac.id/index.php/MGI/a rticle/view/3130

10. Hayyudini D, Suyatno S, 
Dharmawan Y. Hubungan karakteristik ibu, pola asuh dan pemberian imunisasi dasar terhadap status gizi anak usia 12-24 bulan (studi di wilayah kerja puskesmas Kedungmundu kota Semarang tahun 2017). J Kesehat Masy [Internet]. 2017 Oct 1;5(4):788-800. Available from:

https://ejournal3.undip.ac.id/index.p hp/jkm/article/view/18779

11. Picauly I, Toy SM. Analisis Determinan Dan Pengaruh Stunting Terhadap Prestasi Belajar Anak Sekolah Di Kupang Dan Sumba Timur, Ntt. J Gizi dan Pangan. 2013;8(1):55-62.

12. Pusung BL, Malonda NSH, Momongan N. Hubungan antara riwayat imunisasi dan penyakit infeksi dengan status gizi pada balita usia 24-59 bulan di wilayah kerja puskesmas Touluaan kabupaten Minahasa Tenggara. J Kesmas. 2018;7(4).

13. Kasim E, Malonda N, Amisi M. Hubungan Antara Riwayat Pemberian Imunisasi dan Penyakit Infeksi dengan Status Gizi pada Anak Usia 24-59 Bulan di Kecamatan Ratahan Kabupaten Minahasa Tenggara. J Bios Logos. 2019;9(1):34-43. 